\title{
High glucose dephosphorylates serine 46 and inhibits p53 apoptotic activity
}

Alessia Garufi ${ }^{1,2}$ and Gabriella D'Orazi ${ }^{1,2^{*}}$

\begin{abstract}
Background: In response to diverse genotoxic stimuli p53 is activated as transcription factor to exert its tumor-suppressor function. P53 activation requires protein stabilization, nuclear localization and posttranslational modifications in key residues that may influence p53 selection of target genes. Among them, serine 46 (Ser46) phosphorylation is considered specific for apoptotic activation. Hyperglicaemia, the high blood glucose condition, may negatively affect tumor response to therapies through several mechanisms, conferring resistance to drug-induced cell death. However, whether high glucose might modify p53Ser46 phosphorylation has never been addressed.

Methods and results: Here, we performed biochemical and molecular analyses in different cancer cell lines treated with chemotherapy in the presence or absence of high glucose condition. Analyses of p53 posttranslational modifications showed that drug-induced p53Ser46 phosphorylation was reduced by high glucose. Such reduction depended by high glucose-induced calyculin A-sensitive phosphatase(s), able to specifically target p53Ser46 phosphorylation. The specific effect on Ser46 phosphorylation was addressed by analysing Ser15 phosphorylation that instead was not modified by high glucose. In agreement, a constitutively phosphorylated Ser46D p53 mutant was resistant to high glucose. As a consequence of phosphoSer46 impairment, high glucose reduced the tumor cell response to drugs, correlating with reduced p53 apoptotic transactivation. The drug-induced apoptotic cell death, reduced by high glucose, was finally restored by the phosphatase inhibitor calyculin A.

Conclusions: These data indicate that high glucose specifically inhibited Ser46 phosphorylation thus reducing p53 apoptotic activity. These results uncover a new mechanism of p53 inactivation providing an interesting novel molecular link between metabolic diseases such as diabetes or obesity and tumor progression and resistance to therapies.
\end{abstract}

Keywords: p53, Ser46 phosphorylation, Hyperglicemia, Phosphatase, Calyculin A, Apoptosis, Chemotherapy, Gene transcription

\section{Background}

P53 is the major tumor-suppressor that functions within an extensive signalling network [1]. In response to several types of genotoxic stress p53 is activated to control genes that lead to different cellular outcome such as cell-cycle arrest and apoptosis. In this manner, p53 protects cells from tumorigenesis, reduces tumor progression, and activates tumor cell response to anticancer drugs [2]. P53 activation is achieved at multiple levels including protein stability and sub-cellular localization

\footnotetext{
* Correspondence: gdorazi@unich.it

'Department of Experimental Oncology, Regina Elena National Cancer Institute, Rome, Italy

${ }^{2}$ Department of Medical, Oral and Biotechnological Sciences, University "G. d'Annunzio", Via dei Vestini, 31, 66013 Chieti, Italy
}

leading to transcriptional activation of sequence-specific target genes with specific oncosuppressor functions [3]. Apoptosis has been suggested to be a major contribution to p53-mediated suppression of tumor formation [4] and resistance to apoptosis is one of the major hurdles in the treatment of cancer [5]. TP53 posttranslational modifications, such as phosphorylation and acetylation of specific residues, are thought to play a role for the choice among the different biological functions regulated by p53 [6]. It has been proposed that phosphorylation of p53 at Nterminal serine 46 (Ser46) is a necessary step for inducing apoptosis in response to severe DNA damage by shifting from cell-cycle-related to apoptosis-related gene transcription $[7,8]$. P53 phosphorylated at Ser46 modulates less sensitive gene regulatory elements such as 
those that control genes encoding proapoptotic proteins including p53AIP1, PIG3, Bax, Noxa, Puma and KILLER/ DR5 [7,9-12], or the antiapoptotic factor galectin-3 [13], leading to irreversible apoptosis. To add a layer of complexity, some studies have shown that p53 Ser46 phosphorylation is dispensable for transcriptional activation [14]. However, a defect in Ser46 phosphorylation has been observed in tumor cells that are resistant to p53-mediated apoptosis, and this defect contributes to chemoresistance or the acquisition of the resistance to p53 gene transfer [15]. On the contrary, a mutant active form of p53, in which Ser46 is replaced with phenylalanine (p53-46 F), has been shown to induce apoptosis more effectively that wild-type (wt) p53 [16], while studies with knock-in mice expressing the human TP53 gene with Ser46A mutation (non phosphorylatable Ser46), reduced p53 apoptotic transactivation [17], strengthening the apoptotic role for this p53 posttranslational modification.

Hyperglicaemia is a pathophysiological condition characterized by high blood glucose concentration that has been shown to predispose to cancer development and progression [18]. Hyperglicaemia is often a consequence of a Western lifestyle that is associated with metabolic syndrome and type- 2 diabetes or obesity. Epidemiological evidence suggests that patients with diabetes mellitus are at significantly higher risk of developing many types of cancers [19]. Foods with high glycemic load are most closely correlated with higher recurrence of colon cancer [20]. Moreover, hyperglicaemia may inhibit tumor response to therapies conferring resistance to chemotherapy-induced cell death [21-24]. Glucose metabolism has been shown to reduce p53-dependent transcription of apoptotic Puma gene, although the molecular mechanism of such inactivation was not elucidated [25]. Therefore, in this study we sought to investigate in vitro whether high glucose (HG) culture condition might target p53Ser46 in cancer cells and have an impact on p53-induced drug response.

\section{Materials and methods}

\section{Cell culture and reagents}

In this study human lung cancer H1299 (p53 null), colon cancer RKO and HCT116 (carrying wild-type p53), HCT116-p53 $3^{-/}$, lung cancer A549 and ovarian cancer 2008 cells (carrying wild-type p53), were used. Cells were routinely cultured in DMEM (Life TechnologyInvitrogen) containing $1 \mathrm{~g} / \mathrm{L} \mathrm{D}$-glucose, supplemented with $10 \%$ heat-inactivated fetal bovine serum (FBS) plus glutamine and antibiotics. For high glucose (HG) treatment, cells were transferred to DMEM containing $4.5 \mathrm{~g} / \mathrm{L}$ D-glucose (Life Technology-Invitrogen), as previously reported [22,23], supplemented with $2 \%$ FBS for $24 \mathrm{~h}$ before adding chemotherapeutic drugs Adriamycin (ADR) or cisplatin (CDDP) to the culture media respectively at $2 \mu \mathrm{g} / \mathrm{ml}$ and $5 \mu \mathrm{g} / \mathrm{ml}$ for additional $16 \mathrm{~h}$ (for ChIP assay) or $24 \mathrm{~h}$ (for all the other experiments). Phosphatase inhibitor calyculin A [26] (Sigma) was added at $1 \mathrm{nM}$ along with drugs.

\section{Viability and tunel assays}

For viability assay, subconfluent cells were plated in duplicate in $60 \mathrm{~mm}$ Petri dishes and $24 \mathrm{~h}$ later transferred to HG medium or DMEM with $1 \mathrm{~g} / \mathrm{L}$ D-glucose, both containing $2 \%$ FBS. The day after, cells were treated with ADR or CDDP for 24 hours. Both floating and adherent cells were collected and cell viability was determined by Trypan blue exclusion by direct counting with a haemocytometer, as reported [27].

Tunel assays were essentially performed as described [28]. Briefly, $4 \times 10^{4}$ cells were spun on a slide by cytocentrifugation and subsequently fixed in $4 \%$ paraformaldheyde for $30 \mathrm{~min}$ at room temperature. After rinsing with PBS, the samples were permeabilized in a solution of $0.01 \%$ Triton X-100 in sodium citrate for $2 \mathrm{~min}$. Samples, washed with PBS, were then incubated in the TUNEL reaction mix for $1 \mathrm{~h}$ at $37^{\circ} \mathrm{C}$ according to the manufacture's instructions (Roche, Germany). Cells were counter-stained with Hoechst 33342 before analysis with a fluorescent microscope (Zeiss).

\section{Chromatin-immunoprecipitation (ChIP) assay}

ChIP assay was carried out essentially as previously described [29]. Protein complexes were cross-linked to DNA in living cells by adding formaldehyde directly to the cell culture medium at $1 \%$ final concentration. Chromatin extracts containing DNA fragments with an average size of 500 bp were incubated overnight at $4^{\circ} \mathrm{C}$ with milk shaking using polyclonal anti-p53 antibody (FL393, Santa Cruz Biotechnology). Before use, protein G (Pierce) was blocked with $1 \mu \mathrm{g} / \mu \mathrm{L}$ sheared herring sperm DNA and $1 \mu \mathrm{g} / \mu \mathrm{L}$ BSA for $3 \mathrm{~h}$ at $4^{\circ} \mathrm{C}$ and then incubated with chromatin and antibodies for $2 \mathrm{~h}$ at $4^{\circ} \mathrm{C}$. PCR was performed with HOT-MASTER Taq (Eppendorf) using $2 \mu \mathrm{L}$ of immuniprecipitated DNA and promoter-specific primers. Immunoprecipitation with non-specific immunoglobulins (IgG; Santa Cruz Biotechnology) was performed as negative controls. The amount of precipitated chromatin measured in each PCR was normalized with the amount of chromatin present in the input of each immunoprecipitation. PCR products were run on a $2 \%$ agarose gel and visualized by ethidium bromide staining using UV light.

\section{Transfection and luciferase assays}

Cells were transiently transfected with the cationic polymer LipofectaminePlus method (Invitrogen) according to the manufacturers' instructions. Luciferase activity was measured in H1299 cells co-transfected with $\beta$-galactosidase ( $\beta$-gal), wtp53 or the constitutively phosphorylated p53Ser46D expression vectors, along with the synthetic 
PG13-luc reporter or the natural p53AIP1-luc reporter. Luciferase activity was assayed on whole cell extracts and the luciferase values normalized to $\beta$-gal activity and protein content and expressed as relative luciferase unit (RLU), as previously described [29].

\section{RNA extraction and semi-quantitative reverse transcription (RT)-PCR analysis}

Cells were harvested in TRIzol Reagent and total RNA was isolated following the manufacturer's instructions (Invitrogen). The first strand cDNA was synthesized from $2 \mu \mathrm{g}$ of total RNA with MuLV reverse transcriptase kit (Applied Biosystems). Semi-quantitative Reverse-Transcribed (RT)-PCR was carried out by using Hot-Master Taq polymerase (Eppendorf) with $2 \mu \mathrm{l}$ cDNA reaction and genes specific oligonucleotides under conditions of linear amplification. PCR products were run on a $2 \%$ agarose gel and visualized with ethidium bromide. The housekeeping $28 \mathrm{~S}$ gene, used as internal standard, was amplified from the same cDNA reaction mixture. Densitometric analysis was applied to quantify mRNA levels compared to control gene expression.

\section{Western blotting}

Western immunoblotting derived from whole cell lysates or nuclear/cytoplasmic extracts was performed as previously described [30]. Total cell extracts were prepared by incubation in lysis buffer $(50 \mathrm{mM}$ Tris- $\mathrm{HCl}, \mathrm{pH} 7.5$, $150 \mathrm{mM} \mathrm{NaCl}, 5 \mathrm{mM}$ EDTA, $150 \mathrm{mM} \mathrm{KCl}, 1 \mathrm{mM}$ dithiothreitol, 1\% Nonidet P-40) and a mix of protease inhibitors and resolved by $9-12 \%$ SDS-polyacrilamide gel electrophoresis. Proteins were transferred to a polyvinylidene difluoride membrane (PVDF, Millipore) and membranes were blocked with $5 \%$ nonfat dry milk in PBS and incubated with the primary antibodies followed by an anti-immunoglobulin-G-horseradish peroxidase antibody (BioRad).

For subcellular fractionation, cells were trypsinized, rinsed with PBS and collected by centrifugation. Cells were then suspended in hypotonic buffer $(10 \mathrm{mM}$ HEPES, $\mathrm{pH}$ 7.9, $10 \mathrm{mM} \mathrm{KCl,} 0.1 \mathrm{mM}$ EDTA, $0.1 \mathrm{mM}$ EGTA) and placed on ice for $15 \mathrm{~min}$. NP40 was added to a final concentration of $0.5 \%$. Cells were spun top speed for $30 \mathrm{~s}$ before the supernatant (cytoplasmic fraction) was collected. The remaining pellet was washed with hypotonic buffer, resuspended in RIPA buffer, sonicated and spun at $14000 \mathrm{~g}$ for $15 \mathrm{~min}$ to remove debris and collect the supernatant (nuclear fraction). We confirmed the separation of the cytoplasmic and nuclear fractions by Western immunoblotting of tubulin (cytoplasmic marker) and lamin A (nuclear marker), respectively.

The following primary antibodies were used: mouse monoclonal p53 (DO1) (Santa Cruz Biotechnology), rabbit polyclonal phospho-Ser46 (Cell Signalling and Santa Cruz) and phospho-Ser15 (Cell Signalling), mouse monoclonal anti-poly(ADP-ribose) polymerase (PARP, cleaved form, BD Pharmingen), rabbit polyclonal anti-lamin $\mathrm{A}$ and mouse monoclonal anti- $\beta$-actin (Santa Cruz), followed by an anti-immunoglobulin-G-horseradish peroxidase secondary antibody (BioRad). Immunoreactivity was detected by enhanced chemiluminescence (ECL) (Amersham GE Healthcare).

\section{Statistics}

Each experiment, unless specified, was performed at least three times. All experiments results were expressed as the arithmetic mean; standard deviation (S.D.) of measurement was shown. Student's $t$ test was used for statistical significance of the difference between groups. Statistical analysis was performed using analysis of variance at $5 \%$ $(\mathrm{p} \leq 0.05)$ or $1 \%(\mathrm{p} \leq 0.01)$.

\section{Results}

\section{Glucose reduces chemotherapy-induced cell death}

To look into the influence of high glucose (HG) levels on resistance to chemotherapeutic agents, several human cancer cells, carrying wild-type (wt) p53, including RKO and HCT116 colon cancer, 2008 ovarian cancer and A549 lung cancer cells, were incubated with chemotherapeutic drugs, such as adryamicin (ADR) or cisplatin (CDDP), before or after treatment with HG (4.5 g/L Dglucose) condition. The $4.5 \mathrm{~g} / \mathrm{L}$ and the $1 \mathrm{~g} / \mathrm{L} \mathrm{D}$-glucose concentration for, respectively, high glucose (HG) and low glucose condition were chosen according to previous studies $[22,23]$. Cancer cell death induced by apoptotic doses of chemotherapy, as previously reported [10,31], was significantly reduced when cells were transferred into HG culture condition (Figure 1A). Of note, HG per se did not modify cancer cell viability, indicating that it was instead triggering molecular mechanisms of resistance to antitumor drugs. To verify that HG might target p53 activity, HCT116-p $53^{-1-}$ cells were tested in comparison with wtp53-carrying cells. Cell viability assay shows that the slight drug-induced cell death in HCT116-p53 ${ }^{-/-}$cells was not modified by HG condition (Figure 1A), suggesting that p53 inhibition might have a role in HG-induced chemoresistance. Moreover, the ADR-induced cleavage of the apoptotic marker PARP was strongly reduced by HG condition (Figure 1B).

\section{HG reduces $\mathrm{p} 53$ apoptotic transactivation}

Therefore, to evaluate the influence of HG on p53 activity we first analysed the p53/DNA binding activity by ChIP assay and, after that, p53 transactivation. We found that the efficient p53 in vivo recruitment onto apoptotic p53AIP1 and Puma promoters in response to ADR was strongly reduced by $\mathrm{HG}$ culture condition (Figure 2A). On the other hand, HG did not modify the 


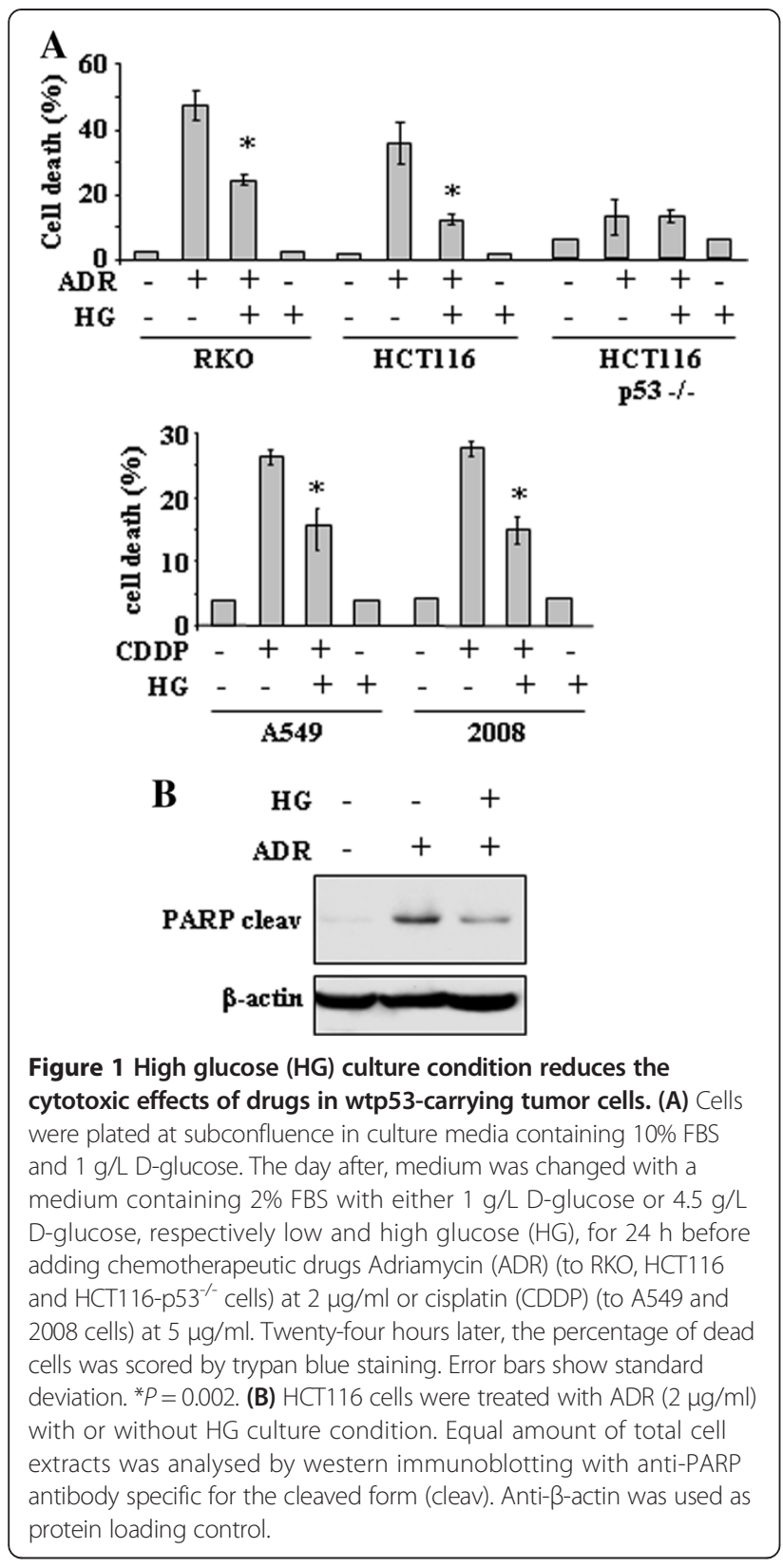

p53 binding to non apoptotic promoters such as $M D M 2$, $p 21$, and $p 53 R 2$ (Figure 2A). The p53 transcriptional activity was then evaluated by luciferase assay following transient co-transfection of $\mathrm{H} 1299$ cells with the synthetic p53 responsive PG13-luc reporter and wtp53 expression vector. As shown in Figure 2B, p53 induced PG13-luc activity that was remarkably reduced by HG condition. In a similar manner, HG reduced the p53-induced transcriptional activity of the natural p53AIP1-luc reporter (Figure 2B). In vivo analyses of mRNA levels show that drug-induced upregulation of p53 apoptotic target genes such as p53AIP1 and Puma was strongly impaired by HG condition, while $p 21$ expression was not modified
(Figure 2C). These results indicate that p53 apoptotic transcriptional activity was impaired by HG culture condition.

\section{HG does not impair p53 nuclear translocation, rather it reduces serine 46 (Ser46) phosphorylation}

To identify the mechanism underlying impaired p53 apoptotic activity in HG condition, we first examined p53 stability and nuclear localization, which are at the basis of p53 transcriptional activation [6]. Western blotting of nuclear and cytoplasmic cell extracts show that p53 underwent efficient stabilization and nuclear localization following drug treatment, and both conditions were not modified by HG (Figure 3A). These results indicate that the impaired p53 binding to apoptotic promoters following HG, seen above, does not depend on defect of p53 nuclear accumulation. Therefore, we next sought to evaluate whether p53 posttranslational modifications were targeted by HG. In particular, we analysed Ser46 phosphorylation (p-Ser46), since p53AIP1 is a specific target of p-Ser46 [7] and we found above that p53AIP1 expression was inhibited by HG. Western blotting of total cell extracts with phospho-specific antibodies show that drug-induced pSer46 was strongly reduced by HG condition (Figure 3B). The specific effect of HG on p-Ser46 was addressed by analysing p-Ser15 that, in comparison, was not modified (Figure 3B). Moreover HG did not alter p53 levels (Figure 3B), indicating that it specifically affected p53Ser46 phosphorylation. In support of our hypothesis that p-Ser46 is a target of HG, we analysed p53AIP1-luc promoter activity following transfection of a constitutively phosphorylated p53Ser46D expression vector. The results show that p53AIP1-luc activity, induced by Ser46D expression, was not inhibited by HG condition, compared to the wtp53induced p53AIP1-luc activity (Figure 3C). These data indicate that HG specifically inhibited Ser46 phosphorylation though reducing p53-induced apoptotic luciferase activity.

\section{Inhibition of HG-induced phosphatase(s) by the use of calyculin A restores $\mathrm{p}-\mathrm{Ser} 46$}

The above data show that dephosphorylation of p53 at the key Ser46 residue limited p53 apoptotic transcriptional activity. To get insight into the mechanism of Ser46 dephosphorylation by HG we used calyculin A, a cell-permeable phosphatase inhibitor which has been shown to enhance ionizing radiation-induced p-Ser46 [26]. Western blotting show that drug-induced p-Ser46, strongly reduced by HG, was efficiently rescued by calyculin A (Figure 4A). At molecular level, ADR-induced p53 apoptotic-gene expression, inhibited by HG, was rescued by calyculin A (Figure 4B). These data suggest that one or more calyculin A-sensitive phosphatases were triggered by HG to deregulate drug-induced p-Ser46 of p53; however, as calyculin A not only counteracted the negative effect of HG on p53 transactivation but further increased it, it is 


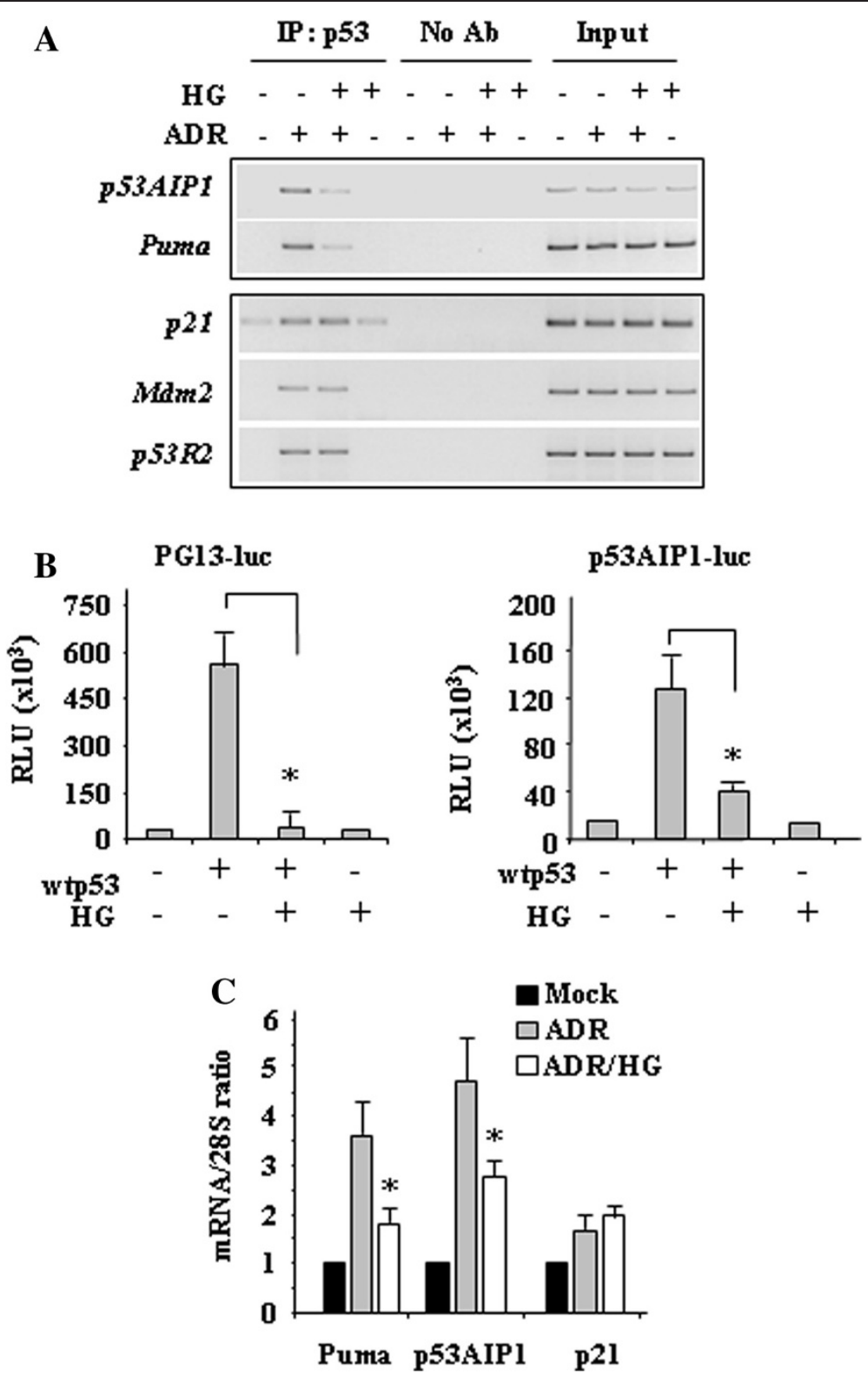

Figure 2 High glucose (HG) culture condition reduces the p53/DNA binding and transactivation functions mainly on apoptotic genes. (A) ChIP analyses performed with anti-p53 antibody on HCT116 cells treated with ADR $(2 \mu \mathrm{g} / \mathrm{ml})$ in 2\% FBS culture medium with or without HG. PCR analyses were performed on the immunoprecipitated DNA samples using specific primers for the p53 target promoters. A sample representing linear amplification of the total chromatin (Input) was included as control. Additional controls included immunoprecipitation performed with nonspecific immunoglobulins (No Ab). (B) H1299 cells were transiently co-transfected with PG13-luc or p53AIP1-luc reporters and wtp53 plasmid. Twenty-four hours after transfection culture medium was changed with a medium containing $2 \%$ FBS with or without HG. Results, normalized to $\beta$-gal activity are the mean \pm S.D. of three independent experiments performed in duplicate. ${ }^{*} P=0.001$. (C) RNA samples were extracted by HCT116 cells treated as in Figure 1 and used for RT-PCR. The mRNA level of specific p53 target genes was analysed by densitometry and plotted as the expression ratio to control $28 \mathrm{~S}$ expression. Data are the mean \pm S.D. of two independent experiments. ${ }^{*} P=0.001$.

tempting to speculate the presence of phosphatases also independently of HG condition. Previous studies, including ours, have shown that phosphorylation of p53 at Ser46 activates the apoptotic cascade $[7,9,10,14,16]$, therefore, we investigated the effect of HG on drug-induced apoptotic cell death by Tunel staining. We found that the
ADR-induced Tunel positivity was reduced by HG condition and efficiently rescued by calyculin A treatment (Figure 4C). These results indicate that HG dephosphorylated Ser46 in p53 likely through activation of one or more calyculin A-sensitive phosphatases that impaired p53 apoptotic activity. 


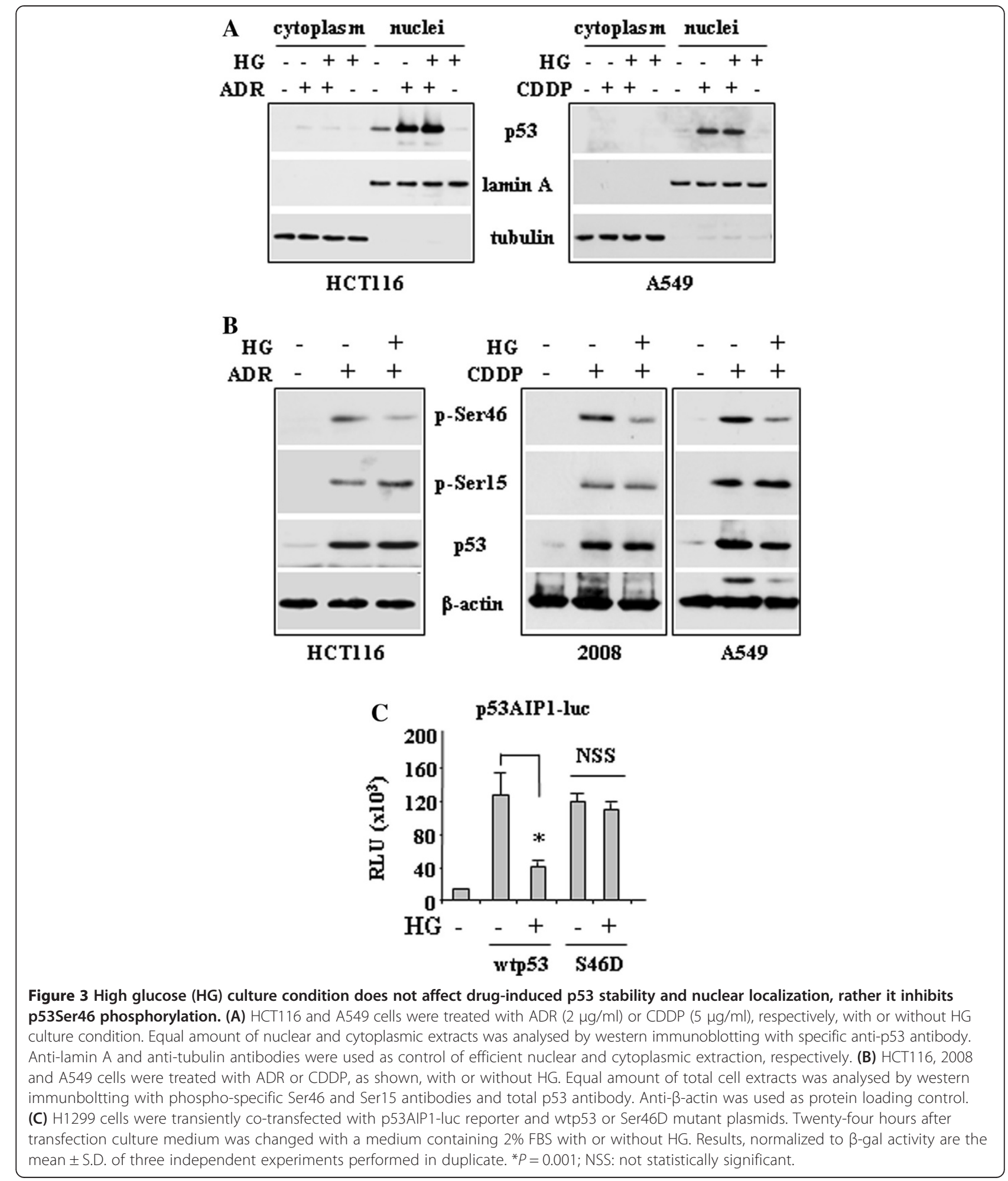

\section{Discussion}

Here, for the first time a novel glucose-mediated mechanism of p53 inhibition was shown: HG culture condition impaired p53Ser 46 phosphorylation and consequently reduced p53 apoptotic activity, attenuating drug-induced cell death. Importantly, the use of the phosphatase inhibitor calyculin A was sufficient to restore Ser46 phosphorylation and drug-induce cell death, indicating that Ser46 dephosphorylation was the mechanism of inhibition of p53 apoptotic activity following HG condition. 

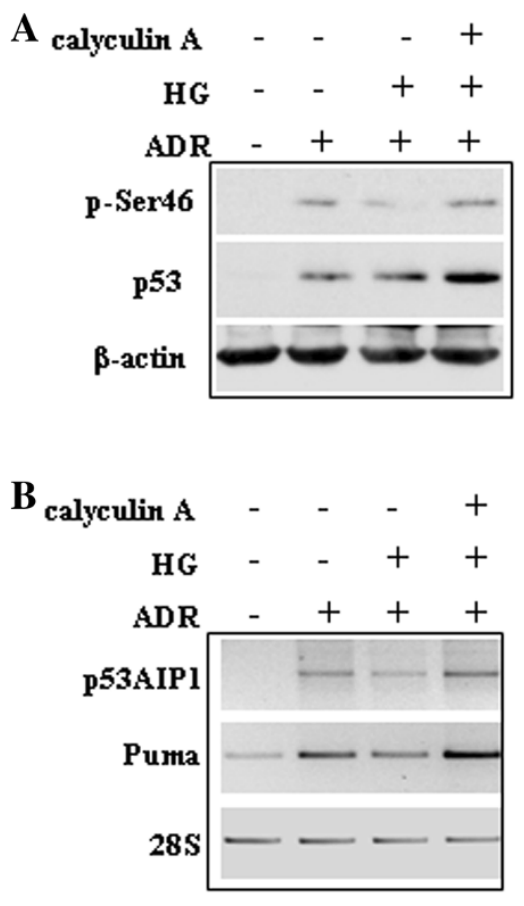

C

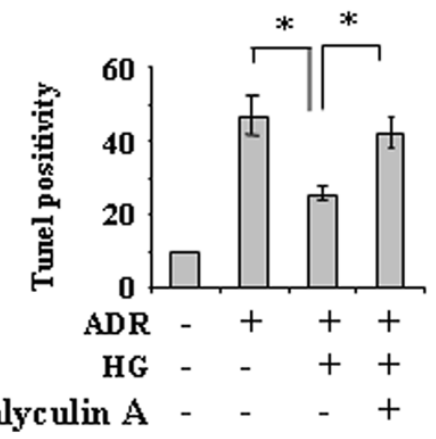

- Mock $\square$ ADR $\square$ ADR/HG $\triangle A D R / H G / c a l y c u l i n$ A
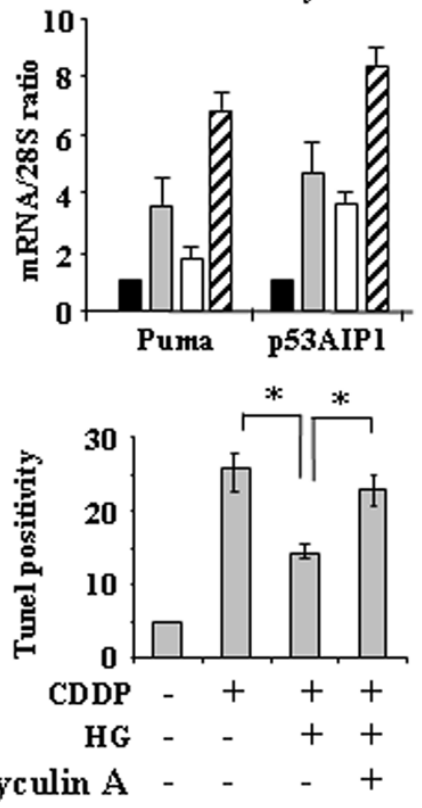

Figure 4 High glucose (HG) induces calyculin A-sensitive phospahatase(s) able to target p-Ser46. (A) HCT116, cells were treated with ADR with or without HG; phosphatase inhibitor calyculin A was added at $1 \mathrm{nM}$ along with ADR. Equal amount of total cell extracts was analysed by western immunboltting with phospho-specific Ser46 antibody and total p53 antibody. Anti- $\beta$-actin was used as protein loading control. (B) RNA samples were extracted by HCT116 cells treated as in (A) and used for RT-PCR of p53 target gene expression. $28 \mathrm{~S}$ levels were analyzed as internal control (left panel). Densitometric analysis is shown in the right panel and plotted as the expression ratio to control 285 expression. (C) Tunel assay of HCT116 and 2008 cells treated with ADR and CDDP, respectively, with or without HG condition. Phosphatase inhibitor calyculin A was added at $1 \mathrm{nM}$ along with drugs. The results shown are the percentage of Tunel positive cells and are representative of two independent experiments performed in duplicates, \pm S.D. ${ }^{*} P=0.001$.

In the clinic, the functional status of p53 has been associated with the prognosis, progression, and therapeutic response of tumors [32]. P53 is the most inactivated tumorsuppressor in cancers, therefore, understanding the many ways of p53 regulation is physiologically important because it may affect tumor prognosis and therapy [33]. Thus, many studies in the last years have addressed the reactivation of mutant p53 (see ref. [34,35] and refs. herein) or the reconstitution of wtp53 [36-39] because tumors containing wtp53 are usually more sensitive to radiotherapy or chemotherapy than those bearing inactive p53 [40]. TP53 is mainly mutated, however, other inactivation involve p53 protein deregulation. In this regard, the present results support a significant conceptual advance in the area of $\mathrm{p} 53$ protein inactivation even in the absence of p53 mutations. Human p53 harbors an array of serine/ threonine phosphorylation sites that span the entire protein but are mainly concentrated in the $\mathrm{N}$-terminal transactivation domain and the C-terminal regulatory domain Each site/modification may fine-tune p53 function, dictating p53 activity in a promoter-specific manner [41]. Ser46 has recently been the focus of much attention because it has been associated with p53 apoptotic function and its inhibition associated with increased chemoresistance 
[7-9,15,16]. The functional significance of Ser46 may be also deduced by the codon 47 polymorphism that, although rare, has been shown to interrupt Ser46 phosphorylation and decrease p53-dependent apoptotic activity [42].

Glucose metabolism has been shown to impact p53 function. Glucose restriction can activate p53 apoptotic pathway [43] that is indeed inhibited in cells lacking a functional p-Ser46 [44] and can reduce mutant p53 prooncogenic function [45], in line with the beneficial antitumor effect of caloric/dietary restriction [46]. On the other hand, high glucose has been shown to reduce p53dependent transcription of apoptotic Puma gene, although the molecular mechanism of such inactivation was not elucidated [25]. Here we show that one or more calyculin A-sensitive phosphatases were induced by HG to target p53 at Ser46 thus reducing tumor cell response to anticancer drugs. Further studies will be needed to elucidate the phosphate(s) involved in p53Ser46 inactivation by HG and develop a way to block it, as potential application in clinical practice. In this regard, high glucose has been shown to activate PP2A [47] which has been shown to dephosphorylate p53 at Ser46 [26], making it a good candidate to be analysed in future studies. Moreover, the partial recovery of drug-induced apoptosis following the rescue of p-Ser46, suggests that additional mechanisms of chemoresistance triggered by HG might exist and negatively impact the tumor response to therapies.

In addition, our findings raise more questions for further studies; for example, it would be interesting to investigate whether the HG-induced phosphatase directly dephosphorylates p53Ser 46 or rather it targets the upstream kinases claimed to phosphorylate p53 at Ser46, such as homeodomain-interacting protein kinase 2 (HIPK2) [9], ATM [48], DNA-dependent protein kinase [49], protein kinase $C \delta$ [50], and dual-specificity tyrosinephosphorylation-regulated kinase 2 (DYRK2) [51]. Such redundancy in kinases able to phosphorylate p53 at Ser46 support its key role in apoptosis. The possibility that HG might inhibit one of those kinases, rather than targeting directly Ser46, comes from the result that Ser46 phosphorylation is not completely abolished by HG (Figure 3B, Figure 4A). One of the most studied Ser46 kinase, also by us, is HIPK2 which is activated by several cellular stress including chemotherapeutic agents and whose inhibition has been shown to profoundly restrain p53 apoptotic activity. As HIPK2 inhibition impairs Ser46 but also Lys382 acetylation it would be interesting to evaluate the effect of HG on p53 acetylation and its impact on drug response [52,53]. It has been recently shown that reactive oxygen species (ROS) may inhibit HIPK2 kinase activity [54] and, interestingly, a pathophysiological condition that induces ROS production is high glucose [55], strongly supporting more extensive studies about the involvement of HIPK2 in p53Ser46 inactivation following HG condition. In preliminary experiments, thus, we have found that HIPK2 kinase activity was reduced by HG and that also Lys 382 acetylation of p53 was impaired by HG (unpublished results).

The acquisition of drug resistance of cancer cells is a big problem in anticancer therapy because it can block apoptotic pathways and/or increase the ability to repair DNA, ensuring the survival of cancer. Understanding the many mechanisms of drug resistance is therefore the subject of intense studies [56]. In this regard, our results show that hyperglycemia may have a negative effect in cancer treatment by inhibiting p53Ser46 apoptotic activity. These results may have clinical impact because highlight how controlling blood glucose levels may have important therapeutic implications in cancer patients.

\section{Abbreviations}

ADR: Adryamicin; CDDP: Cisplatin; ChIP: Chromatin-immunoprecipitation; HG: High glucose; p-Ser46: Serine 46 phosphorylation; RLU: Relative luciferase unit; RT-PCR: Reverse transcription polymerase chain reaction; wtp53: Wild-type p53.

\section{Competing interests}

The authors declare that they have no competing interests.

\section{Authors' contributions}

AG and GDO performed experiments and analyzed data; GDO conceived the experiments and wrote the paper. Both authors read and approved the final manuscript.

\section{Acknowledgements}

This study was funded by the Italian Association for Cancer Research (AIRC, IG11377) Grant. We thank Maria Laura Avantaggiati for critical discussion and Maria Pia Gentileschi for technical assistance. The p53AIP1-luc reporter was kindly provided by Prof. H. Arakawa (National Cancer Center, Tokyo, Japan); the phosphorylation mimic p53Ser46D mutant was kindly provided by Dr. L. Mayo (Case Western Reserve University, Cleveland, Ohio, USA).

Received: 3 September 2014 Accepted: 19 September 2014 Published online: 27 September 2014

\section{References}

1. Kruse JP, Gu W: Modes of p53 regulation. Cell 2009, 137:609-622

2. Vousden $\mathrm{KH}$, Prives $\mathrm{C}$ : Blinded by the light: The growing complexity of p53. Cell 2009, 137:413-431.

3. Bode AM, Dong Z: Post-translational modification of p53 in tumorigenesis. Nat Rev Cancer 2004, 4:793-805.

4. Attardi L, DePinho A: Conquering the complexity of p53. Nat Genet 2004, $36: 7-8$.

5. Hanahan D, Weinberg RA: Hallmarks of cancer: the next generation. Cell 2011, 144:646-674.

6. Brooks CL, Gu W: Ubiquitination, phosphorylation and acetylation: the molecular basis for p53 regulation. Curr Opin Cell Biol 2003, 15:164-171.

7. Oda K, Arakawa H, Tanaka T, Matsuda K, Tanikawa C, Mori T, Nishimori H, Tamai K, Tokino T, Nakamura Y, Taya Y: p53AIP1, a potential mediator of p53-dependent apoptosis, and its regulation by Ser-46-phosphorylated p53. Cell 2000, 102:849-862.

8. Mayo LD, Rok Seo Y, Jackson MW, Smith ML, Rivera Guzman JR, Koegaonkar CK, Donner DB: Phosphorylation of human p53 at serine 46 determines promoter selection and whether apoptosis is attenuated or amplified. J Biol Chem 2005, 280:25953-25959.

9. D'Orazi G, Cecchinelli B, Bruno T, Manni I, Higashimoto Y, Saito S, Gostissa M, Coen S, Marchetti A, Del Sal G, Piaggio G, Fanciulli M, Appella E, Soddu S: Homeodomain-interacting protein kinase 2 phosphorylates p53 at Ser46 and mediates apoptosis. Nat Cell Biol 2002, 4:11-19. 
10. Di Stefano V, Rinaldo C, Sacchi A, Soddu S, D'Orazi G: Homeodomaininteracting protein kinase-2 activity and p53 phosphorylation are critical events for cisplatin-mediated apoptosis. Exp Cell Res 2004, 293:311-320.

11. Pistritto G, Puca R, Nardinocchi L, Sacchi A, D'Orazi G: HIPK2-induced p53Ser46 phosphorylation activates the KILLER/ DR5-mediated caspase-8 extrinsic apoptotic pathway. Cell Death Differ 2007, 14:1837-1839.

12. Smeenk L, van Heeringen SJ, Koeppel M, Gilbert B, Janssen-Megens E, Stunnenberg HG, Lohrum M: Role of p53 serine 46 in p53 target gene regulation. PLOS One 2011, 6:e17574.

13. Cecchinelli B, Lavra L, Rinaldo C, lacovelli S, Gurtner A, Gasbarri A, Ulivieri A, Del Prete F, Trovato M, Piaggio G, Bartolazzi A, Soddu S, Sciacchitano S: Repression of the anti-apoptotic molecule Galectin-3 by HIPK2-activated p53 is required for p53-induced apoptosis. Mol Cell Biol 2006, 26:4746-4757.

14. Thompson T, Tovar C, Yang H, Carvajal D, Vu BT, Xu Q, Wahl GM, Heimbrook DC, Vassilev LT: Phosphorylation of p53 on key serines is dispensable for transcriptional activation and apoptosis. J Biol Chem 2004, 102:53015-53022.

15. Ichwan SJ, Yamada S, Sumrejkanchanakij P, Ibrahim-Auerkari E, Eto K, Ikeda MA: Defect in serine 46 phosphorylation of p53 contributes to acquisition of p53 resistance in oral squamous cell carcinoma cells. Oncogene 2006, 25:1216-1224.

16. Nakamura Y, Futamura M, Kamino H, Yoshida K, Nakamura Y, Arakawa H: Identification of p53-46 F as super p53 with an enhanced ability to induce p53-dependent apoptosis. Cancer Sci 2006, 97:633-641.

17. Feng $L$, Hollstein $M, X u Y$ : Ser 46 phosphorylation regulates $p 53-$ dependent apoptosis and replicative senescence. Cell Cycle 2006, 5:2812-2819.

18. Duan W, Shen X, Lei J, Xu Q, Yu Y, Li R, Wu E, Ma Q: Hyperglycemia, a neglected factor during cancer progression. BioMed Res Inter 2014, 2014:461917.

19. Cebioglu M, Schild HH, Golubnitschaja O: Cancer predisposition in diabetics: risk factors considered for predictive diagnostics and targeted preventive measures. EPMA J 2010, 1:130-137.

20. Meyerhardt JA, Sato K, Niedzwiecki D, Ye C, Saltz LB, Mayer RJ, Mowat RB, Whittom R, Hantel A, Benson A, Wigler DS, Venook A, Fuchs CS: Dietary glycemic load and cancer recurrence and survival in patients with stage III colon cancer: findings from CALGB 89803. J Natl Cancer Inst 2012, 104:1702-1711.

21. Zeng L, Biernacka KM, Holly JMP, Jarret C, Morrison AA, Morgan A, Winters ZE, Foulstone EJ, Shield JP, Perks CM: Hyperglicaemia confers resistance to chemotherapy on breast cancer cells: the role of fatty acid synthase. Endocr Relat Cancer 2010, 17:539-551.

22. Biernacka KM, Uzoh CC, Zeng L, Persad RA, Bahl A, Gillatt D, Perks CM, Holly JMP: Hyperglicaemia-induced chemoresistance of prostate cancer cells due to IGFBP2. Endocrinol J 2013, 20:741-751.

23. Ma YS, Yang IP, Tsai HL, Huang CW, Juo SHH, Wang JY: High glucose modulates antiproliferative effect and cytotoxicity of 5-Fluorouracil in human colon cancer cells. DNA and Cell Biol 2014, 33:64-72.

24. Shao $Y$, Ling CC, Liu XQ: High concentrations of glucose suppress etoposide-induced cell death of B-cell lymphoma through BCL-6. Biochem Biophys Res Commun 2014, 450:227-233.

25. Zhao Y, Coloff JL, Ferguson EC, Jacobs SR, Cui K, Rathmell JC: Glucose metabolism attenuates p53 and PUMA-dependent cell death upon growth factor deprivation. J Biol Chem 2008, 283:36344-36353.

26. Mi J, Bolesta E, Brautigan DL, Larner JM: PP2A regulates ionizing radiationinduced apoptosis through Ser46 phosphorylation of p53. Mol Cancer Ther 2009, 8:135-140.

27. Garufi A, D'Orazi V, Arbiser JL, D'Orazi G: Gentian violet induces p53 transactivation in cancer cells. Int J Oncol 2014, 44:1084-1090.

28. Nardinocchi L, Puca R, D'Orazi G: HIF-1a antagonizes p53-mediated apoptosis by triggering HIPK2 degradation. Aging-US 2011, 3:33-43.

29. Nardinocchi L, Puca R, Sacchi A, Rechavi G, Givol D, D'Orazi G: Targeting hypoxia in cancer cells by restoring homeodomain-interacting protein kinase 2 and p53 activity and suppressing HIF-1a. PLOS One 2009, 4:e6819.

30. Di Stefano V, Mattiussi M, Sacchi A, D'Orazi G: HIPK2 inhibits MDM2 gene and protein by, respectively, p53-dependent and independent regulations. FEBS Lett 2005, 579:5473-5480.

31. Puca R, Nardinocchi L, Starace G, Rechavi G, Sacchi A, Givol D, D'Orazi G: Nox 1 is involved in $\mathrm{p} 53$ deacetylation and suppression of its transcriptional activity and apoptosis. Free Rad Biol Med 2010, 48:1338-1346.
32. Soussi T, Beroud C: Assessing TP53 status in human tumors to evaluate clinical outcome. Nat Rev Cancer 2001, 1:233-240.

33. Hoe KK, Verma CS, Lane DP: Drugging the p53 pathway: understanding the route to clinical efficacy. Nat Rev Drug Discov 2014, 13:217-236.

34. Selivanova G, Wiman KG: Reactivation of mutant p53: molecular mechanisms and therapeutic potential. Oncogene 2007, 26:2243-2254.

35. Garufi A, Trisciuoglio D, Porru M, Leonetti C, Stoppacciaro A, D'Orazi V, Avantaggiati M, Crispini A, Pucci D, D'Orazi G: A fluorescent curcuminbased Zn(II)-complex reactivates mutant (R175H and R273H) p53 in cancer cells. J Exp Clin Cancer Res 2013, 32:72

36. D'Orazi G, Marchetti A, Crescenzi M, Coen S, Sacchi A, Soddu S: Exogenous wt-p53 protein is active in transformed cells but not in their nontransformed counterparts: implications for cancer gene therapy without tumor targeting. J Gene Med 2000, 2:11-21.

37. Martins $C P$, Martins $C P$, Brown-Swigart $L$, Evan Gl: Modeling the therapeutic efficacy of p53 restoration in tumors. Cell 2006, 127:1223-1234.

38. Ventura A, Kirsch DG, McLaughlin ME, Tuveson DA, Grimm J, Lintault L, Newman J, Reczek EE, Weissleder R, Jacks T: Restoration of p53 function leads to tumor regression in vivo. Nature 2007, 445:661-665.

39. Xue W, Zender L, Miething C, Dickins RA, Hernando E, Krizhanovsky V, Cordon-Cardo C, Lowe SW: Senescence and tumour clearance is triggered by p53 restoration in murine liver carcinomas. Nature 2007, 445:656-660

40. Mandinova A, Lee SW: The p53 pathway as a target in cancer therapeutics: obstacles and promise. Science 2011, 3:1-7.

41. Dai C, Gu W: p53 post-transaltional modification: deregulated in tumorigenesis. Trends Mol Med 2010, 16:528-536.

42. Li X, Dumont P, Della Pietra A, Shetler C, Mutphy ME: The codon 47 polymorphism in p53 is functionally significant. J Biol Chem 2005, 280:24245-24251.

43. Okoshi R, Ozaki T, Yamamoto H, Ando K, Koida N, Ono S, Koda T, Kamijo T, Nakagawara A, Kizaki H: Activation of AMP-activated protein kinase induces p53-dependent apoptotic cell death in response to energetic stress. J Biol Chem 2008, 283:3979-3987.

44. Garufi A, Ricci A, Trisciuoglio D, lorio E, Carpinelli G, Pistritto G, Cirone M, D'Orazi G: Glucose restriction induces cell death in parental but not in homeodomain-interacting protein kinase 2-depleted RKO colon cancer cells: molecular mechanisms and therapeutical implications for tumor therapy. Cell Death Dis 2013, 4:e639.

45. Rodriguez OC, Choudhury S, Kolukula V, Vietsch EE, Catania J, Preet A, Reynoso K, Bargonetti J, Wellstein A, Albanese C, Avantaggiati ML: Dietary downregulation of mutant p53 levels via glucose restriction. Cell Cycle 2012, 11:4436-4446.

46. Pallavi R, Giorgio M, Pelicci PG: Insights into the beneficial effect of caloric/dietary restriction for a healthy and prolonged life. Front Physiol 2012, 3:318

47. Castermans D, Somers I, Kriel J, Louwet W, Wera S, Versele M, Janssens V, Thevelein JM: Glucose-induced posttranslational activation of protein phosphatases PP2A and PP1 in yeast. Cell Res 2012, 22:1058-1077.

48. Saito S, Goodarzi AA, Higashimoto Y, Noda Y, Lees-Miller SP, Appella E, Anderson CW: ATM mediates phosphorylation at multiple p53 sites, including Ser(46), in response to ionizing radiation. J Biol Chem 2002, 277:12491-12494.

49. Komiyama S, Taniguchi S, Matsumoto Y, Tsunoda E, Ohto T, Suzuki Y, Yin HL, Tomita M, Enomoto A, Morita A, Suzuki T, Ohtomo K, Hosoi Y, Suzuki N: Potentiality of DNA-dependent protein kinase to phosphorylate Ser46 of human p53. Biochem Biophys Res Commun 2004, 323:816-822.

50. Yoshida K, Liu H, Miki Y: Protein kinase $\mathrm{C} \delta$ regulates Ser46 phosphorylation of p53 tumor suppressor in the apoptotic response to DNA damage. J Biol Chem 2006, 281:5734-5740.

51. Taira N, Nihira K, Yamaguchi T, Miki Y, Yoshida K: DYRK2 is targeted to the nucleus to control p53 via ser46 phosphorylation in the apoptotic response to DNA damage. Mol Cell 2007, 25:725-738.

52. Puca R, Nardinocchi L, Sacchi A, Rechavi G, Givol D, D'Orazi G: HIPK2 modulates p53 activity towards pro-apoptotic transcription. Mol Cancer 2009, 8:85.

53. D'Orazi G, Rinaldo C, Soddu S: Updates on HIPK2: a resourceful oncosuppressor for clearing cancer. J Exp Clin Cancer Res 2012, 31:63.

54. de la Vega L, Grishina I, Moreno R, Krüger M, Braun T, Schmitz ML: A redoxregulated SUMO/acetylation switch of HIPK2 controls the survival threshold to oxidative stress. Mol Cell 2012, 46:1-12. 
55. Yu T, Robotham JL, Yoon Y: Increased production of reactive oxygen species in hyperglycemic conditions requires dynamic change of mitochondrial morphology. Proc Natl Acad Sci U S A 2006, 103:2653-2658.

56. Niero EL, Rocha-Sales B, Lauand C, Araujo Cortez B, de Souza Medina M, Rezende-Teixeira P, Shiniti Urabayashi M, Martens AA, Neves JH, MachadoSantelli GM: The multiple facets of drug resistance: one history, different approaches. J Exp Clin Cancer Res 2014, 33:37.

doi:10.1186/s13046-014-0079-4

Cite this article as: Garufi and D'Orazi: High glucose dephosphorylates

serine 46 and inhibits p53 apoptotic activity. Journal of Experimental \&

Clinical Cancer Research 2014 33:79.

\section{Submit your next manuscript to BioMed Central and take full advantage of:}

- Convenient online submission

- Thorough peer review

- No space constraints or color figure charges

- Immediate publication on acceptance

- Inclusion in PubMed, CAS, Scopus and Google Scholar

- Research which is freely available for redistribution 